\title{
Diabetic intestinal growth adaptation and glucagon-like peptide 2 in the rat: effects of dietary fibre
}

\author{
J Thulesen, B Hartmann, C Nielsen, J J Holst, S S Poulsen
}

\begin{abstract}
BackgroundlAims-Dietary fibre influence growth and function of the upper gastrointestinal tract. This study investigates the importance of dietary fibre in intestinal growth in experimental diabetes, and correlates intestinal growth with plasma levels of the intestinotrophic factor, glucagon-like peptide 2 (GLP-2). Methods-Male Wistar rats were randomised to the following groups: two streptozotocin-diabetic and two control groups fed either a fibre-containing or a fibre-free diet for three weeks. Intestinal weight, length, and morphometric data (villus height, villus area, crypt depth) were measured. Blood samples were obtained after two weeks for measurement of GLP-2 and enteroglucagon (glicentin, oxyntomodulin).

Results-The mean daily consumption of food in the two diabetic groups was $40 \%$ higher than in controls. In diabetic rats fed fibre, the increase in intestinal weight from day 0 to 20 was sixfold greater than that of the controls and small intestine weight per $\mathrm{cm}$ length was increased by $50 \%$. In the diabetic rats fed a fibre-free diet, intestinal growth was $\mathbf{3 0 \%}$ less than in diabetic rats fed fibre, and intestinal weight increased only threefold compared with controls. Morphometric data showed that the intestinal increase in diabetic rats fed fibre was due primarily to growth of the mucosal layer. Villus height and crypt depth increased $60 \%$ and $40 \%$ respectively, but by only $20 \%$ in fibre-free diabetic rats. The plasma levels of GLP-2 parallelled diabetic intestinal growth, whereas plasma levels of enteroglucagon increased regardless of the extent of intestinal growth. Conclusions-Intestinal growth in experimental diabetes is strongly influenced by the presence of dietary fibre. The effect may be mediated by GLP-2.

(Gut 1999;45:672-678)
\end{abstract}

Keywords: small intestine; intestinal adaptation; growth factors; dietary fibre; diabetes mellitus; rat

The presence of luminal nutrients and especially non-digestible components of the diet, such as dietary fibres which are not digested by mammalian enzymes, is pivotal in intestinal growth and adaptation. ${ }^{1-6}$ However, the mechanisms by which nutrients influence growth and function of the gastrointestinal tract are poorly understood and likely to be multifactorial. ${ }^{5}$ Some of the trophic effects of fibres may be due to the formation of short chain fatty acids (SCFAs) by bacterial fermentation of the fibre polysaccharides in the caecum and colon..$^{7-9}$ SCFAs, which are organic fatty acids with 1-6 carbons, stimulate intestinal mucosal growth in the small bowel and the colon of the rat. ${ }^{10-15}$ However, the trophic effects of SCFAs in the upper gastrointestinal tract and in the colon differ in that systemic mediators seem to be involved in growth stimulation of the small intestine, ${ }^{410131617}$ whereas the trophic effects in the colon are mediated locally. ${ }^{12}{ }^{15} 16$ Thus the trophic effects of fibres in the small intestine may be hormonally mediated through the release of gastrointestinal regulatory peptides, several of which appear to be trophic to the small intestine. ${ }^{18} 19$

A mounting body of evidence indicates that glucagon-like peptide 2 (GLP-2) is an important intestinotrophic factor. ${ }^{20-22}$ It is one of the proglucagon derived peptides secreted from the enteroendocrine L-cells, ${ }^{23}{ }^{24}$ which are predominantly located in the ileum and the proximal part of the colon. ${ }^{25}$ Parenteral administration of GLP-2 in mice induces growth of the small intestine. ${ }^{20-22}$ Treatment of rodents with GLP-2 after resection of the small intestine or after induction of experimental colitis has been shown to improve the absorptive quality and mucosal healing of the remnant intestinal tissue. $^{2627}$

In order to investigate the trophic effects of dietary fibres and possible mediators of their trophic effects in the small intestine, we used an experimental model with marked intestinal growth, the untreated diabetic rat, fed either a diet containing fibre or without fibre. Intestinal growth, described in morphological detail, was correlated with changes in plasma concentrations of GLP-2 and enteroglucagon (glicentin, oxyntomodulin), in order to test the hypothesis that the trophic effects of dietary fibre on the upper gastrointestinal tract are regulated by intestinal proglucagon derived peptides.

\section{Methods}

ANIMALS

The animal studies were approved by the Danish National Committee for Animal Studies. Adult male Wistar rats (Panum Institute, Copenhagen, Denmark), weighing about $240-250 \mathrm{~g}$, were housed individually in

Abbreviations used in this paper: GLP, glucagon-like peptide; SCFA, short chain fatty acid. 
cages with wire mesh bases in air conditioned $\left(21^{\circ} \mathrm{C}\right)$ and humidity controlled $(55 \%)$ rooms with a light/dark cycle of 12 hours each. The animals were randomly allocated to the following groups: control groups fed a fibrecontaining diet (Altromin 1314; Altromin, Lage, Germany) or a fibre-free diet (Altromin 1013); experimental diabetic groups fed a fibre-containing diet (Altromin 1314) or a fibre-free diet (Altromin 1013). The fibre part of Altromin 1314 comprises mainly grass and lucerne meals. These components contain lignin (grass meal, $52 \mathrm{~g} / \mathrm{kg}$; lucerne meal, 85 $\mathrm{g} / \mathrm{kg}$ ) as insoluble fibre, and cellulose (grass meal, $17.5 \%$; lucerne meal, 19\%) and hemicellulose (grass meal, $11.8 \%$; lucerne meal, $15.6 \%$ ) as soluble fibres. The crude fibre levels in both meals are $26 \%$. Each group contained at least 12 rats, half of which were used for blood samples after two weeks (day 13) and the other half for tissue samples after three weeks (day 20). All rats were allowed free access to food and water. Daily food consumption was measured. A fifth group of rats $(n=8)$ was used to measure intestinal weight and length on day 0 as baseline values.

\section{EXPERIMENTAL DIABETES}

A single intraperitoneal injection of $70 \mathrm{mg} / \mathrm{kg}$ streptozotocin (Sigma Chemical Co, St Louis, Missouri, USA), dissolved in freshly prepared $50 \mathrm{mmol} / 1$ citrate buffer ( $\mathrm{pH} 4.0$ ) immediately before administration was given to 28 rats. The injections were given at 1600 hours. Blood concentrations of glucose were measured 48 hours later (day 0) in blood obtained from the cut tip of the tail and measured by the glucose oxidase method using a One Touch II instrument (Lifescan, Milpitas, California, USA). Only rats with a blood glucose concentration above $18 \mathrm{mmol} / \mathrm{l}$ were included in the diabetic groups. Blood glucose concentrations were subsequently measured once a week in the morning. Control animals received an equivalent volume of citrate buffer and had their blood glucose concentrations measured as described for the diabetic groups.

BLOOD SAMPLES AND ASSAYS

Blood samples for measurement of plasma concentrations of GLP-2 and enteroglucagon (glicentin, oxyntomodulin) were obtained from rats on day 13. The rats were anaesthetised with barbiturate (Brietal, Methohexital; Eli Lilly Co, Indianapolis, Indiana, USA; 50 $\mathrm{mg} / \mathrm{kg}$, intraperitoneally). Blood samples were obtained from the inferior vena cava and collected into chilled tubes containing in final concentrations, EDTA $(3.9 \mathrm{mmol} / \mathrm{l})$ and valine-pyrolidide (a dipeptidyl peptidase IV inhibitor; $0.01 \mathrm{mmol} / \mathrm{l}$ ) (gift from $\mathrm{Dr} T$ Hughes, Novartis, Institute of Biomedical Research, Summit, New Jersey, USA). Dipeptidyl peptidase IV is a serine protease which appears to be responsible for degradation of the intact and biologically active GLP-2-(1-33) to the metabolite and N-terminally truncated form, GLP-2-(3-33). ${ }^{28}$ Proglucagon derived peptides were measured after extraction of plasma with $75 \%$ (final concentration) ethanol.
GLP-2 immunoreactivity was analysed as previously described ${ }^{29}$ with an $\mathrm{N}$-terminal specific radioimmunoassay measuring only intact GLP-2-(1-33). The detection limit was below $5 \mathrm{pmol} / \mathrm{l}$ and the intra-assay coefficient of variation (all analyses were performed in the same assay run) was $2.3 \%$ at a concentration of 40 pmol/1. Pancreatic glucagon was measured using antiserum 4305, monoiodinated ${ }^{125} \mathrm{I}-$ labelled glucagon (gift from Novo Nordisk, Bagsvaerd, Denmark), and highly purified porcine glucagon as standard (Novo Nordisk). ${ }^{30} 31$ Antiserum 4305 requires the free C-terminus of glucagon for binding. In the pancreas, glucagon is formed by post-translational processing of proglucagon. In the gut, the main product of proglucagon is glicentin, but part of this peptide is cleaved further to oxyntomodulin. ${ }^{32}$ Total glucagon immunoreactivity was measured using a side viewing antiserum 4304, which cross reacts with equal strength with all peptides that contain the glucagon sequence-that is, pancreatic glucagon, glicentin, and oxyntomodulin. Plasma concentrations of enteroglucagon (glicentin, oxyntomodulin) were then obtained by subtracting pancreatic from total glucagon immunoreactivity. The experimental detection limits for both glucagon assays were below 2 pmol/1.

\section{TISSUE SAMPLES}

Tissue samples were obtained after three weeks (day 20) from rats anaesthetised as described above. The stomach and the small intestine (from oesophagus to the ileocaecal junction) and the entire colon were then removed separately. The mesentery was trimmed off and luminal contents were removed by flushing with cold $4 \%$ paraformaldehyde and gentle manipulation. The tissues were weighed and the entire length of the small intestine and the colon was then measured after vertical suspension with a $10 \mathrm{~g}$ weight in the distal end. ${ }^{1}$ Tissue samples of the caecum and the proximal, mid and distal parts of the small intestine and colon were fixed in $4 \%$ paraformaldehyde.

HISTOLOGICAL SECTIONS AND MORPHOMETRIC ESTIMATES

The three segments of the small intestine and two segments of the large intestine were dehydrated and then embedded in paraffin. For comparative purposes, sections from each animal were obtained from identical anatomical positions representing proximal jejunum, distal jejunum, and distal ileum of the small intestine and the proximal and distal segments of the colon. The paraffin embedded samples were cut perpendicular to the axis of their length into $10 \mu \mathrm{m}$ sections using a microtome. The sections were then placed on gelatine coated glass and stained with haematoxylin and eosin. The sections were examined using a Zeiss Axiophot microscope (Carl Zeiss, Oberkocken, Germany) connected to a high resolution camera (Hamamatsu C2400; Hamamatsu Photonics, Hamamatsu City, Japan). The cross sectional area of the mucosa and muscle layers and villus height and crypt depth were measured using an image analysis system (NIH 
Table 1 Blood concentrations of glucose (mmol/l) from day 0 to day 20 in control and diabetic rats fed a fibre-containing diet or a fibre-free diet

\begin{tabular}{lllll}
\hline Group & Control, fibre & Control, fibre-free & Diabetes, fibre & Diabetes, fibre-free \\
\hline Day 0 & $4.45(0.27)$ & $4.85(0.14)$ & $19.17(0.88)^{\star \star}$ & $20.43(0.82)^{\star \star}$ \\
Day 6 & $3.92(0.16)$ & $4.36(0.22)$ & $22.28(1.17)^{\star \star}$ & $26.22(2.28)^{\star \star}$ \\
Day 13 & $4.13(0.17)$ & $4.05(0.16)$ & $23.22(1.38)^{\star \star}$ & $23.10(1.23)^{\star \star}$ \\
Day 20 & $4.17(0.16)$ & $4.60(0.10)$ & $24.47(1.89)^{\star \star}$ & $22.54(1.15)^{\star \star}$ \\
\hline
\end{tabular}

Data represent mean $(\mathrm{SEM})$

${ }^{\star \star} \mathrm{p}<0.01 v$ respective controls.

Table 2 Body weight and daily food consumption of control and diabetic rats fed a fibre-containing diet or a fibre-free diet

\begin{tabular}{lllll}
\hline Group & Control, fibre & Control, fibre-free & Diabetes, fibre & Diabetes, fibre-free \\
\hline Body weight (g) & & & & \\
$\quad$ Initial & $256.7(3.4)$ & $255.1(4.5)$ & $253.5(4.3)$ & $255.1(6.2)$ \\
$\quad$ Final & $372.7(10.2)$ & $366.9(10.9)$ & $264.0(10.0)^{\star \star} \dagger$ & $225.5(9.5)^{\star \star}$ \\
Daily food intake & & & & \\
$\quad$ Weight (g) & $22.9(1.0)$ & $23.7(1.1)$ & $33.5(1.4)^{\star \star}$ & $33.7(0.7)^{\star \star}$ \\
$\quad$ Fibre (g) & $1.02(0.05)$ & $0.04(0.002)$ & $1.50(0.06)^{\star \star} \dagger$ & $0.06(0.001)$ \\
$\quad$ Calories (kcal) & $64.0(2.9)$ & $85.1(4.0)$ & $93.8(4.0)^{\star \star} \dagger$ & $117.8(2.43)^{\star \star}$ \\
\hline
\end{tabular}

Data represent mean \pm SEM

${ }_{\star \star \star} \mathrm{p}<0.01 v$ respective controls, $\dagger \mathrm{p}<0.01 v$ diabetes fibre-free.

Image 1.60). The intestinal lumen and the boundaries between the mucosal, submucosal, and muscle layers were outlined by the computer cursor, allowing calculation of the cross sectional area of each layer in the wall. Ten well orientated crypts and villi per segment were randomly selected and measured for villus height and crypt depth. The average area of the villus was calculated as previously described. ${ }^{33}$ The examination and computer analysis of the histological sections were performed without knowledge of the origin of tissue samples.

STATISTICAL ANALYSIS

The results are shown as mean (SEM). Comparison between groups was performed by two way analysis of variance followed by Fisher's protected least significant difference post
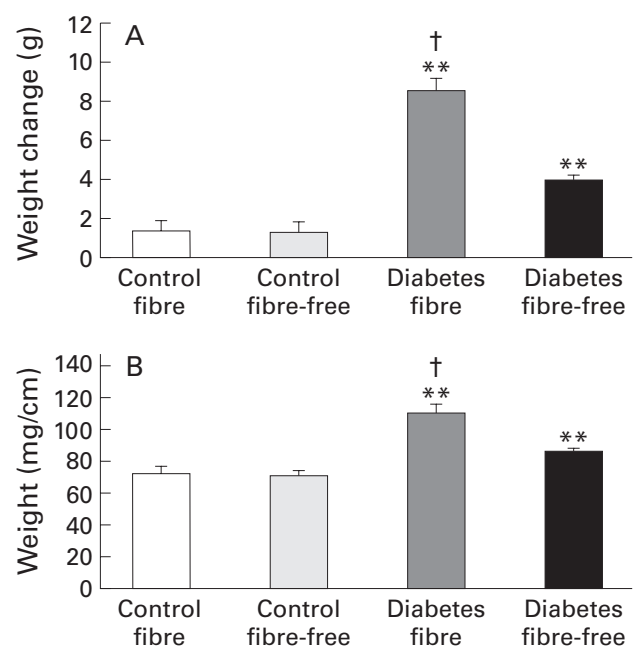

Figure 1 Weight of the small intestine in control and streptozotocin induced diabetic rats fed either a fibre-containing or a fibre-free diet. (A) Mean weight change during the three weeks of the study; (B) weight per cm intestinal tissue; $(C)$ intestinal tissue weight relative to final body weight. Data are expressed as mean (SEM). ${ }_{\star \star *} p<0.01 v$ respective controls; $t_{p}<0.01$ v diabetes fibre-free. hoc analysis. Probability values of $\mathrm{p}<0.05$ were considered significant.

\section{Results}

BLOOD GLUCOSE CONCENTRATION

The blood concentrations of glucose (table 1) in the two control groups were similar and had mean values of about $4 \mathrm{mmol} / \mathrm{l}$ on the days measured. The mean blood glucose concentration in the diabetic rats remained between 19 and $26 \mathrm{mmol} / \mathrm{l}$, and there was no difference between the diabetic groups fed a fibrecontaining diet or a fibre-free diet.

BODY WEIGHT AND FOOD INTAKE

The rats in the control groups gained, on average, $45 \%$ in body weight during the study period (table 2). Diabetic rats fed the fibrecontaining diet gained $4 \%$ in body weight, whereas the diabetic rats fed the fibre-free diet lost $12 \%$ of body weight when compared with the control groups.

The average daily consumption of diet (table 2) was similar in the two diabetic groups and was about $40 \%$ higher than that of the controls. The groups fed the fibre-free diet had a lower dietary intake of fibre, but higher intake of total calories than those fed the fibre-containing diet.

\section{WEIGHT OF SMALL INTESTINE}

In the diabetic rats fed the fibre-containing diet, the increase in weight of the small intestine during the three weeks of the study (fig 1A) was almost sixfold greater than that of the controls. On day 20, the weight of the small intestine, expressed as weight per $\mathrm{cm}$ (fig 1B) and percentage of final body weight (fig 1C), was higher in the diabetic rats fed the fibre-containing diet than in the controls. The increase in intestinal weight in the diabetic rats fed the fibre-free diet was only threefold more than that of the control rats (fig 1A). The final weight of the small intestine (fig $1 \mathrm{~B}, \mathrm{C}$ ) in the diabetic rats fed the fibre-free diet was higher than in the controls but lower than in the diabetic group fed the fibre-containing diet. There was no difference in the intestinal weight parameters between the two control groups. 


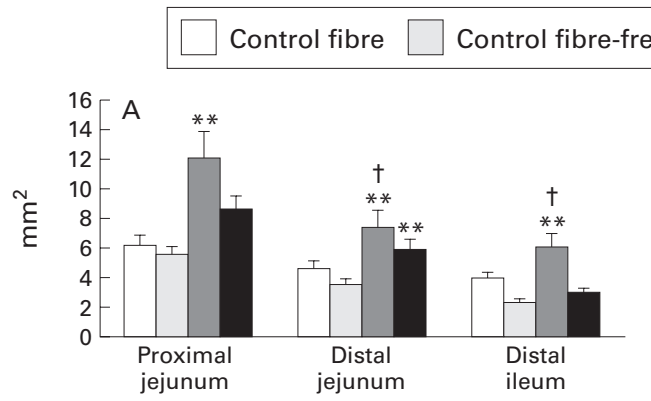

Diabetes fibre

Diabetes fibre-free
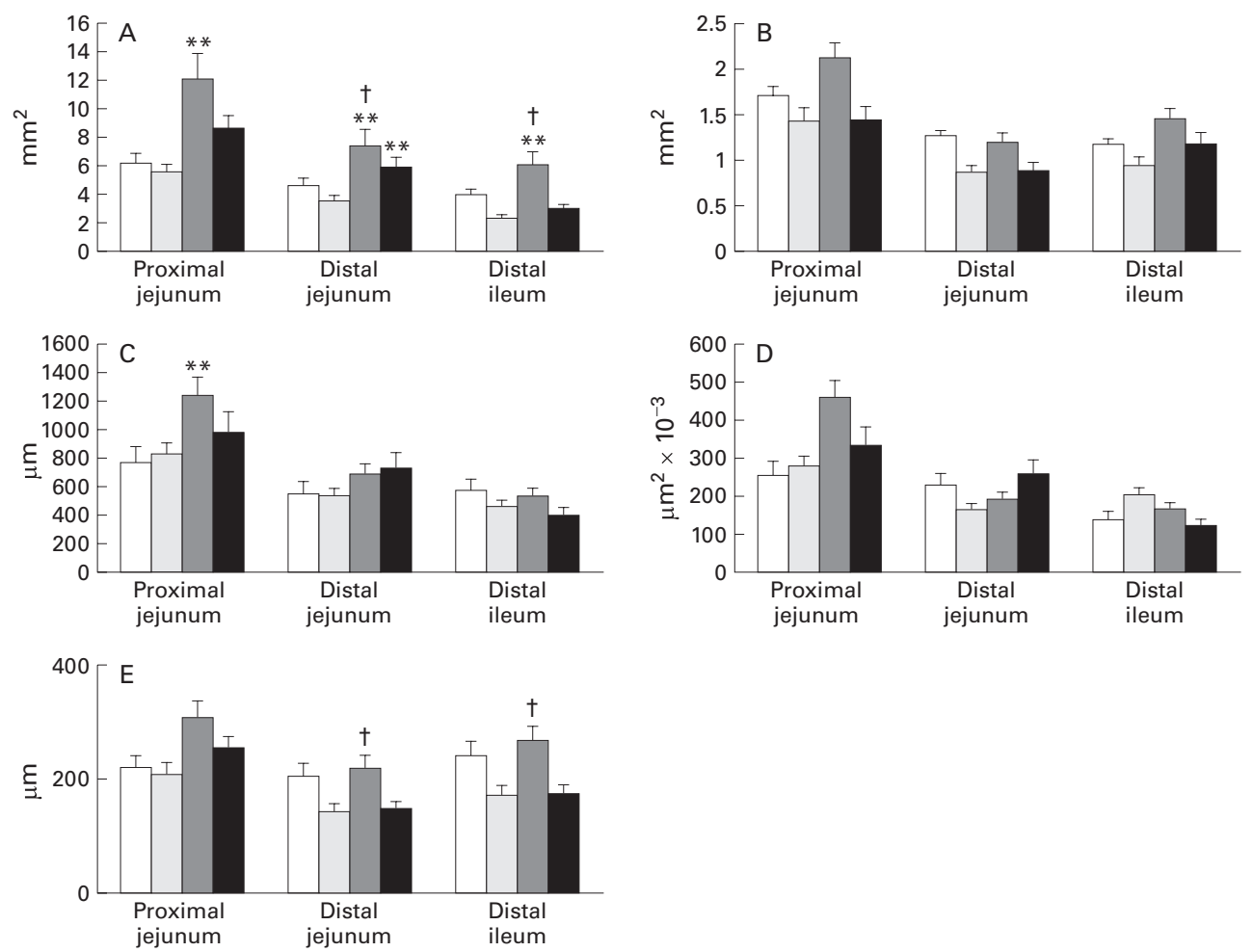

Figure 2 Morphometric estimates of the small intestine in control and streptozotocin induced diabetic rats fed either a fibre-containing or a fibre-free diet. (A) Cross sectional area of the mucosal layer; (B) cross sectional area of the muscle layer; $(C)$ villus height; $(D)$ villus surface area; (E) crypt depth. Data are expressed as mean $(S E M)$. ${ }^{*} p<0.01 \mathrm{v}$ respective controls; $t p<0.01 v$ diabetes fibre-free. Villus height $(C)$ and crypt depth $(E)$ were increased about $60 \%$ and $40 \%$ respectively in the proximal jejunum of the diabetic rats fed the fibre-containing diet compared with controls. The average area of the villi (D) tended to be increased in the proximal jejunum. Villus height (C), villus area (D), and crypt depth $(E)$ were similar in all three intestinal parts examined in the two control groups and the diabetic group fed the fibre-free diet.

MORPHOMETRIC ESTIMATES OF SMALL INTESTINE The growth of the small intestine in the diabetic rats fed the fibre-containing diet was localised to the mucosal layer in all three parts of the small intestine when compared with the controls (fig 2A). The small intestine of the diabetic rats fed the fibre-free diet appeared histologically normal. There was mucosal growth in the proximal intestinal parts, but the area of the mucosal layer was reduced in the distal jejunum and distal ileum compared with the diabetic rats fed the fibre-containing diet. The area of the mucosal layer in the two control groups was similar, although there was a tendency for it to be reduced in the distal ileum of the control rats fed the fibre-free diet. There was no difference in the areas of the muscle layers (fig 2B) between any of the groups.

WEIGHT OF CAECUM

The increase in weight of the caecum during the study period in the diabetic rats fed the fibre-containing diet was almost threefold more than that of the controls (fig 3). There was no increase in caecum weight in the control and diabetic groups fed the fibre-free diet.

WEIGHT OF LARGE INTESTINE

The increase in colon weight in the diabetic rats fed the fibre-containing diet was almost 24 -fold greater than that of the controls (fig

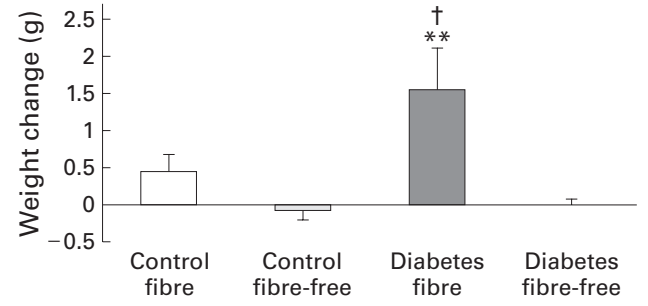

Figure 3 Mean change in caecum weight during the three weeks of study in control and streptozotocin induced diabetic rats fed either a fibre-containing or a fibre-free diet. Data are expressed as mean (SEM). ${ }^{\star \star} p<0.01$ v respective controls; $t p<0.01 v$ diabetes fibre-free.

4A). The control and diabetic groups fed the fibre-free diet both showed a decrease in colon weight. Colonic weight expressed per unit length (fig 4B) was higher in the diabetic group fed fibre than in the diabetic rats fed the fibrefree diet. Expressed as a percentage of final body weight (fig 4C), colon weight in the diabetic rats fed fibre was higher than in the controls and the diabetic group fed the fibre-free diet.

MORPHOMETRIC ESTIMATES OF LARGE INTESTINE There was no difference between any of the groups in the areas of the mucosal/submucosal layers and the muscle layer in the intestinal segments examined (data not shown). The average depth of the colonic crypts was less in 
Figure 4 Weight of the large intestine in control and streptozotocin induced diabetic rats fed either a fibre-containing or a fibre-free diet. (A) Mean weight change during the three weeks of the study; (B) weight per $\mathrm{cm}$ intestinal tissue; $(C)$ intestinal tissue weight relative to final body weight. Data are expressed as mean (SEM). ${ }^{\star *} p<0.01$ v respective controls; $t p<0.01 v$ diabetes fibre-free.
Figure 5 Plasma concentrations of the proglucagon derived peptides, GLP-2 and enteroglucagon (glicentin, oxyntomodulin), on day 13 in control and

streptozotocin induced diabetic rats fed either a fibre-containing or a fibre-free diet. (A) Plasma concentrations of GLP-2;

(B) plasma concentrations of enteroglucagon. Data are expressed as mean (SEM). ${ }^{*} p<0.01$ v respective controls; $t p<0.01$ v diabetes fibre-free.
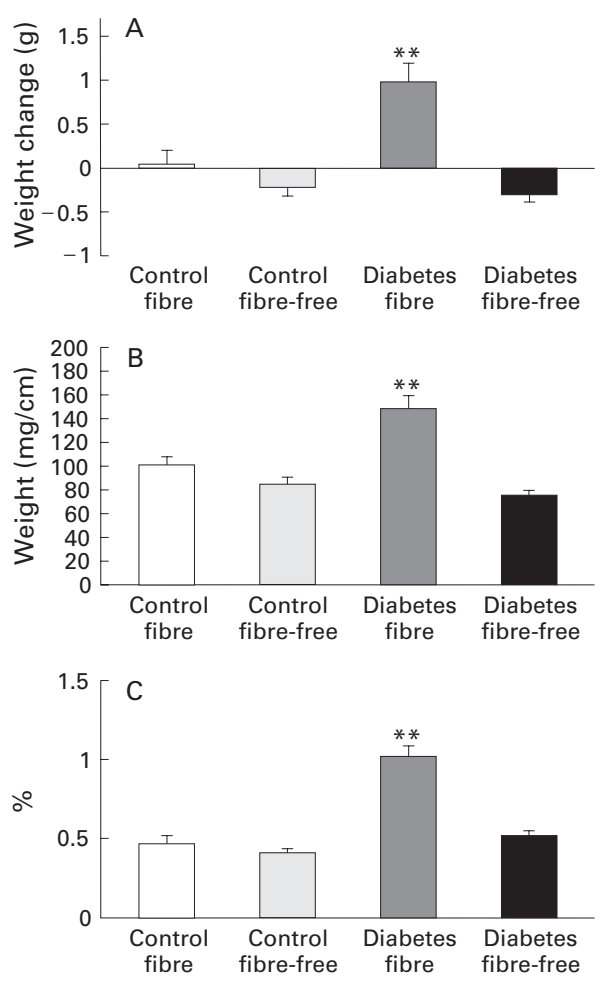

the control and diabetic groups fed the fibre-free diet than in the rats fed the fibre-containing diet (data not shown).

\section{PLASMA CONCENTRATION OF GLP-2}

Mean plasma concentration of GLP-2 on day 13 was $11 \mathrm{pmol} / 1$ in the two control groups fed either fibre-containing or fibre-free diets (fig $5 \mathrm{~A})$. It was almost threefold higher in the diabetic rats fed the fibre-containing diet compared with controls and twofold higher compared with the diabetic rats fed the fibre-free diet. Mean GLP-2 plasma concentration in the diabetic rats fed the fibre-free diet was 15 $\mathrm{pmol} / 1$.

PLASMA CONCENTRATION OF ENTEROGLUCAGON (GLICENTIN, OXYNTOMODULIN)

Plasma enteroglucagon concentration was about $20 \mathrm{pmol} / \mathrm{l}$ in the two control groups (fig 5B). It was almost fourfold higher in both diabetic groups.
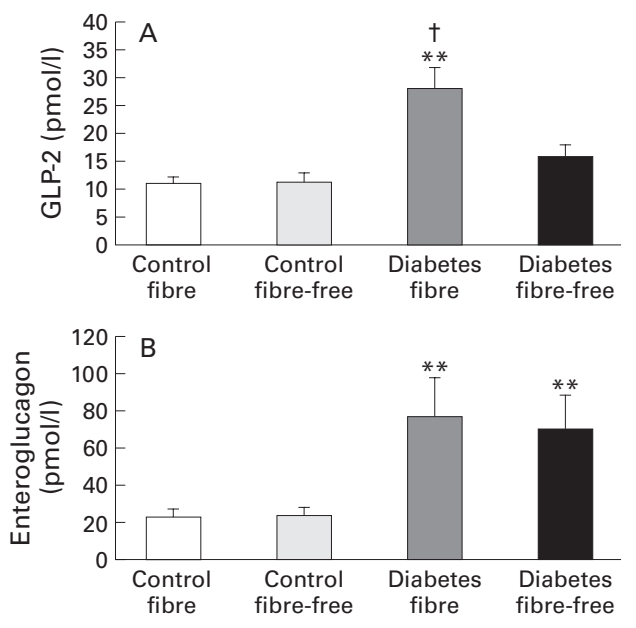

\section{Discussion}

The present data show that diabetic rats fed a fibre-containing diet have pronounced growth of the small intestine, whereas intestinal growth is considerably reduced in diabetic rats fed a fibrefree diet. These data indicate that dietary fibre content is more important in diabetic intestinal growth adaptation than hyperphagia per se. Possible mechanisms of action of dietary fibre in this intestinal growth response include changed circulating levels of the intestinotrophic factor, GLP-2, as diabetic rats fed a fibre-containing diet had increased plasma levels of GLP-2, whereas diabetic rats fed a fibre-free diet had lower levels of GLP-2 in the plasma.

The effects of dietary fibre on the small intestine are probably multifactorial, and may include direct ones on the intestinal tract, as well as indirect ones, through fermentation products and/or the stimulation of trophic hormones. The bulk effect of fibre and unabsorbed nutrients in the lumen of the small intestine do not trigger a proliferative response per se. ${ }^{34}$ However, fibre induced humoral endocrine effects on the tissues of the small intestine seem likely. ${ }^{51135}$ By bacterial fermentation of dietary fibres in the caecum and colon, SCFAs, mainly in the form of butyric, proprionic and acetic acids, are produced ${ }^{8} 9$ which, when exposed directly to colonic epithelium, produce a hyperproliferative response. ${ }^{36}$ Of these volatile fatty acids, butyrate seems to be of primary importance for the colon, as colonocytes metabolise butyrate in preference to other substrates. ${ }^{8}{ }^{36} 37$ Dependence on the intestinal microflora has been demonstrated in studies with germ-free rats fed fibre supplements in the diet, in which no intestinal proliferation is seen in response to dietary fibres. ${ }^{17} 1838$ Furthermore, the intestinal microflora influence the distribution of enteroendocrine cells and the release of some gastrointestinal peptides. ${ }^{39}$ However, the effect on GLP-2 release has not yet been investigated.

SCFAs, administered in physiological doses directly into the caecum of rats, are trophic to both the jejunal and colonic epithelium, ${ }^{14}{ }^{16}$ and intracaecally or intravenously infused SCFAs reduce the extent of intestinal atrophy in rats maintained on total parenteral nutrition. ${ }^{40}$ However, these findings do not explain how SCFAs can affect growth of the upper gastrointestinal tract. One possibility is that cell proliferation is stimulated by the release of a trophic gut peptide. Goodlad et $a l^{4}$ have shown that dietary fibres can stimulate the release of enteroglucagon (glicentin, oxyntomodulin) in rats, and that intracolonic perfusion with glucose induces small intestinal mucosal growth concomitantly withan increase in plasma concentrations of enteroglucagon. ${ }^{41}$ However, the role of enteroglucagon in intestinal growth has been questioned lately. ${ }^{42-44}$

The glucagon precursor synthesised in the intestinal L-cells is post-translationally processed to generate the so called proglucagon derived peptides including enteroglucagon (glicentin, oxyntomodulin), GLP-1 and GLP-2. ${ }^{23} 2432$ GLP-1 is a potent insulinotrophic hormone which also inhibits gastro- 
intestinal secretion and motility. ${ }^{44}$ It may be one of the mediators of the so called "ileal-brake" effect, ${ }^{32}$ but it has no effect on intestinal growth adaptation. ${ }^{20}{ }^{22}$ In contrast, recently published data indicate that GLP-2 is an important intestinotrophic factor. ${ }^{20-22}$ Short term treatment of mice with GLP-2 caused pronounced growth of the small intestine, ${ }^{20-22}$ while it prevented mucosal atrophy in rats on total parenteral nutrition. ${ }^{6}$ In rats with massive resection of the small intestine, treatment with GLP-2 improved the absorptive capacity. ${ }^{26}$ In mice with experimental colitis treated with GLP-2, the mucosal healing of the remaining part of the intestinal tissues improved considerably. ${ }^{27}$ In humans, circulating levels of GLP-2 increase following nutrient ingestion, ${ }^{45}$ while in rats, luminal nutrients and systemic administration of SCFAs stimulate ileal proglucagon mRNA expression in the enteroendocrine L-cells and the release of proglucagon derived peptides. ${ }^{46-48}$ These data and the findings in this study showing intestinal growth concomitantly with fibre ingestion and elevated GLP-2 levels suggest that the trophic effects of dietary fibres on the small intestine may be mediated through the proglucagon derived intestinotrophic factor, GLP-2. Thus this study indicates that dietary fibre participates in regulation of intestinal proglucagon derived peptide biosynthesis and secretion in diabetes.

In this study, plasma concentrations of enteroglucagon were elevated in the diabetic rats in accordance with previous measurements. ${ }^{49}$ Plasma concentrations of enteroglucagon were higher than those of GLP-2 in both diabetic groups. This difference in concentration of the two peptides may be due to differences in plasma elimination rates ${ }^{50}$ which also may explain the differences between plasma concentrations of GLP-1 and enteroglucagon observed in rats after intestinal resection. ${ }^{51}$ However, the present data indicate that plasma concentrations of the biologically active form of GLP-2 parallel intestinal growth in diabetic rats more closely than enteroglucagon. Raised plasma levels of GLP-2 have previously been measured in experimental diabetic rats and a role for GLP-2 in diabetic intestinal growth was implied. ${ }^{52}$ The striking observation of the current study is that a fibre-free diet reduces the extent of diabetic intestinal growth concomitantly with almost normal plasma levels of GLP-2.

The diabetic hyperphagic model has been extensively studied, ${ }^{53}$ and has the advantage that the animal has sustained hyperphagia, while the hyperphagia obtained in animals with lesions in the satiety centre, which is localized to the hypothalamic ventromedial nuclei, subsides once a certain level of obesity is reached. ${ }^{55}$ Furthermore, in hypothalamic hyperphagic rats, the intestine grows in parallel with other tissues. This contrasts with diabetic rats, where intestinal growth is associated with little change or a decrease in body growth. Increased intestinal mass is seen five days after the onset of diabetes and a weight increase up to 140 days after the onset of diabetes has been observed. ${ }^{56}$ The increased workload of the intestinal tissues in the hyperphagia of untreated diabetic animals has been suggested to account for some of the intestinal growth. ${ }^{53}$ However, the present data indicate that the presence of dietary fibre is more important for intestinal growth adaptation than increased workload of the intestinal tissue, especially in the distal part of the small intestine.

Our morphological data show that the growth of the small intestine in the diabetic rat is most pronounced in the proximal part and is primarily due to increased mucosal area. We also observed a progressive decrease in villus height along the small intestine, which is in agreement with previous measurements in diabetic rats with intestinal growth. ${ }^{56}$ Furthermore, we observed that villus height and crypt depth in the distal part of the small intestine are more dependent on the presence of dietary fibre than in the proximal part. This growth response should be compared with that of GLP-2 treated rodents in which the small bowel mass increases, primarily as the result of mucosal growth. ${ }^{22}{ }^{28}$ Even though the morphometric estimates used in this study have been widely used previously, the caveats of Clarke ${ }^{57}$ on the dangers of relying on morphometric estimates should be mentioned. Clarke ${ }^{57}$ suggests the use of other variables such as the product of the rate of blocked-metaphase accumulation per crypt and the crypt/villus ratio. However, in our study, morphometric estimates together with data on intestinal weight and length were combined with measurements of the mucosal area in the different intestinal segments, and we observed a correlation between these parameters.

Caecum weight in the diabetic rats fed the fibre-containing diet was increased, whereas it was unchanged in the diabetic rats fed the fibre-free diet. A strong correlation between the weight of the caecal contents and tissue weight has previously been observed. ${ }^{53}$ Our findings, however, indicate that caecum weight, like small intestine weight, is an adaptive response to an increase in bulk of the contents only if the diet contains fibre. In studies with rats fed an elemental diet, the weight of the distal part of the small intestine and the colon decreases, primarily as the result of muscular atrophy. ${ }^{33}$ In our study, no change in muscle layer area was observed in either the small intestine or the colon in any of the groups. This supports the notion that the intestinal growth in experimental diabetes is primarily due to mucosal hypertrophy and increased intestine length rather than passive dilation of the gut secondary to increased luminal contents.

These observations together indicate that dietary fibre is important in intestinal growth adaptation and that the release of GLP-2 is an important response secondary to the ingestion of fibre. They suggest that mucosal endocrine cells may be triggered by fibres or their metabolites and thereby participate in feedback control of upper gastrointestinal function. The data provide further support for the pivotal role of dietary fibre in intestinal growth and adaptation, and are the first demonstration that 
the enterotrophic action of dietary fibre in diabetes may be mediated by an altered release of GLP-2.

The authors gratefully acknowledge the technical assistance of Hanne Matthiesen, Hannelouise Kissow, and Jette Schousboe. We thank Jim Fielden, Brogaarden, Gentofte, Denmark for the We thank Jim Fielden, Brogaarden, Gentofte, Denmark for the
informative contribution on diet ingredients. This study was informative contribution on diet ingredients. This study was supported by grants from The Danish Biotechnology Centre for Signal-peptide Research, The Danish Medical Research Coun-
cil, The Novo Nordisk Foundation, and The Nordisk Research Foundation.

1 Morin CL, Ling V, Bourassa D. Small intestine and colonic changes induced by a chemically defined diet. Dig Dis $S c i$ 1980;25:123-8.

2 Cassidy MM, Lightfoot FG, Grau LE, et al. Effect of chronic intake of dietary fibres on the ultrastructural topography of rat jejunum and colon: a scanning electron microscopy study. Am 7 Clin Nutr 1981;34:218-28.

3 Sagor GR, Al-Mukhtar MYT, Ghatei MA, et al. The effect of altered luminal nutrition on cellular proliferation and of altered luminal nutrition on cellular proliferation and plasma concentrations of enteroglucagon and gastrin after
small bowel resection in the rat. Br f Surg 1982;69:14-18.

4 Goodlad RA, Lenton W, Ghatei MA, et al. Effects of an elemental diet, inert bulk and different types of dietary ing in the rat and relationship to plasma gastrin, enteroglucagon, and PYY concentrations. Gut 1987;28:171-80

5 Jenkins AP, Thompson RPH. Enteral nutrition and the small intestine. Gut 1994;35:1765-9.

6 Chance WT, Foley-Nelson T, Thomas I, et al. Prevention of parenteral nutrition-induced gut hypoplasia by coinfusion of glucagon-like peptide-2. Am f Physiol 1997;273:G55963.

7 Nyman M, Asp N. Fermentation of dietary fibre components in the rat intestinal tract. Br F Nutr 1982;47:357-66.

8 Cummings JH. Short chain fatty acids in the human colon. Gut 1981;22:763-79.

9 Eastwood MA, Brydon WG, Tadesse K. Effect of fibre on colon. In: Spiller GA, Kay RM, eds. Medical aspects of
dietary fibre. New York: Plenum Medical Book Company, dietary fibre.

10 Sakata T, Yajima T. Influence of short chain fatty acids on the epithelial cell division of digestive tract. $Q \mathcal{F}$ Exp Physiol 1984;69:639-48

11 Johnson IT, Gee JM, Brown JC. Plasma enteroglucagon and small bowel cytokinetics in rats fed soluble nonstarch polysaccharides. Am f Clin Nutr 1988;47:1004-7.

12 Kripke SA, Fox AD, Berman JM, et al. Stimulation of intestinal mucosal growth with intracolonic infusion of shortchain fatty acids. Fournal of Parenteral and Enteral Nutrition 1989;13:109-16.

13 Koruda MJ, Rolandelli RH, Bliss DZ, et al. Parenteral nutrition supplemented with short-chain fatty acids: effect on the small-bowel mucosa in normal rats. Am $\mathcal{F}$ Clin Nutr 1990;51:685-9.

14 Goodlad RA, Chinery R, Lee CY, et al. Effects of short chain fatty acid infusion on the gastrointestinal epithelium of
intravenously fed rats. In: Waldran KW, ed. Food and cancer prevention: chemical and biological aspects. Cambridge, 1993: prevention:

15 Frankel WL, Zhang W, Singh A, et al. Mediation of the trophic effects of short-chain fatty acids on the rat jejunum and colon. Gastroenterology 1994;106:375-80.

16 Sakata T. Stimulatory effect of short-chain fatty acids on epithelial cell proliferation in the rat intestine: a possible explanation for trophic effects of fermentable fibre, gut microbes and luminal trophic factors. Br f Nutr 1987:58 95-103.

17 Goodlad RA, Ratcliffe B, Fordham JP, et al. Does dietary fibre stimulate intestinal epithelial cell proliferation in germ free rats? Gut 1989:30:820-5.

18 Fuller PJ, Beveridge DJ, Taylor RG. Ileal proglucagon gene expression in the rat: characterization in intestinal adaptaexpression in the rat: characterization in intestinal adapta-
tion using in situ hybridization. Gastroenterology 1993:104: 459-66.

19 Williamson RCN, Chir M, Buchholtz TW, et al. Humoral stimulation of cell proliferation in small bowel after transection and resection in rats. Gastroenterology 1978:75 249-54.

20 Drucker DJ, Ehrlich P, Asa SL, et al. Induction of intestinal epithelial proliferation by glucagon-like peptide 2. Proc Natl Acad Sci USA 1996:93:7911-16.

21 Tsai C, Hill M, Drucker DJ. Biological determinants of intestinotrophic properties of GLP-2 in vivo. Am f Physiol 1997:272:G662-8.

22 Tsai C, Hill M, Asa SL, et al. Intestinal growth: properties of glucagon-like peptide-2 in mice. Am f Physiol 1997:273: Elucagon-1i

23 Ørskov C, Holst JJ, Knuhtsen S, et al. Glucagon-like peptides GLP-1 and GLP-2, predicted products of the glucagon gene, are secreted separately from pig small intestine but not pancreas. Endocrinology 1986:119: intestine $1467-75$.

24 Buhl T, Thim L, Ørskov C, et al. Naturally occuring products of proglucagon $111-160$ in the porcine and human small intestine. F Biol Chem 1988:263:8621-4.

25 Varndell IM, Bishop A, Sikri E, et al. Localization of glucagon-like peptide GLP immunoreactants in human gut and pancreas using light and electron microscopic mmunocytochemistry. ff Histochem Cytochem 1985:33: $1080-90$

26 Scott RB, Kirk D, MacNaughton WK, et al. GLP-2 augments the adaptive response to massive intestinal resection in rat. Am f Physiol 1998:275:G911-21.

27 Drucker DJ,Yusta B, Boushey RP, et al. Human [Gly2]GLP-2 reduces the severity of colonic injury in a murine model of experimental colitis. Am $\mathcal{f}$ Physiol 1999:276:G79-91.

28 Drucker DJ, Shi Q, Crivici A, et al. Regulation of the biological activity of glucagon-like peptide 2 in vivo by dipeptidyl peptidase IV. Nature Biotechnology 1997:15:6737.

29 Wøjdemann M, Wettergren A, Hartmann B, et al. Glucagon-like peptide-2 inhibits centrally antral motility in pigs. Scand f Gastroenterol 1998:33:828-32.

30 Holst JJ. Evidence that glicentin contains the entire sequence of glucagon. Biochem f 1980:187:337-43.

31 Holst JJ. Evidence that enteroglucagon (II) is identical with the C-terminal sequence (residues 33-69) of glicentin. Biochem f 1982:207:381-8.

32 Holst JJ. Enteroglucagon. Annu Rev Physiol 1997;59:25771

33 Frankel WL, Zhang W, Singh A, et al. Mediation of the trophic effects of short-chain fatty acids on the rat jejunum and colon. Gastroenterology 1994:106:375-80.

34 Goodlad RA, Wright NA. Effects of addition of kaolin or cellulose to an elemental diet on intestinal cell proliferation in the mouse. Br 7 Nutr 1983:50:91-8.

35 Schrezenmeir J, Kasper H. The influence of dietary-fibre substances on the release of gastrointestinal hormones. In: Kasper H, Goebell H, eds. Colon and nutrition: Falk Symposium 32. Lancaster, MTP Press, 1982:71-6.

36 Sakata T. Stimulatory effect of short-chain fatty acids on epithelial cell proliferation of isolated and denervated jejunal segment of the rat. Scand $\mathcal{F}$ Gastroenterol 1989;24:886nal seg.

37 Roediger WE. Utilization of nutrients by isolated epithelial cells of the rat colon. Gastroenterology 1982;83:424-9.

38 Komai M, Takehisa F, Kimura S. Effect of dietary fiber on intestinal epithelial cell kinetics of germ-free and conventional mice. Nutrition Reports International 1982;26:25561

39 Uribe A, Alam M, Johansson O, et al. Microflora modulates endocrine cells in the gastrointestinal mucosa of the rat. Gastroenterology 1994;107:1259-69.

40 Koruda MJ, Rolandelli RH, Bliss DZ, et al. Parenteral nutrition supplemented with short-chain fatty acids: effect on the small-bowel mucosa in normal rats. Am $\mathrm{f}$ Clin Nutr 1990;51:685-9.

41 Miazza BM, Al-Mukhtar MYT, Salmeron M, et al. Hyperenteroglucagonemia and small intestinal mucosal growth after colonic perfusion of glucose in rats. Gut 1985; 26:518-26.

42 Gregor M, Stallmach A, Menge $\mathrm{H}$, et al. The role of gut-glucagon-like immunoreactants in the control of gastrointestinal epithelial cell renewal. Digestion 1990;46: $59-65$

43 Gee JM, Lee-Finglas W, Wortley GW, et al. Fermentable carbohydrates elevate plasma enteroglucagon but high viscosity is also necessary to stimulate small bowel mucosal cell proliferation in rats. $\mathcal{F}$ Nutr 1996;126:373-9.

44 Ghatei MA, Ratcliffe, Bloom SR, et al. Fermetable dietary fibre, intestinal microflora and plasma hormones in the rat. Clin Sci (Colch) 1997;93:109-12.

45 Hartmann B, Wøjdemann M, Deacon CF, et al. Metabolism of endogenous and exogenous glucagon-like peptide-2 in humans [abstract]. Dig Dis Sci 1998;43:A212.

46 Reimer RA, McBurney MI. Dietary fiber modulates intestinal proglucagon messenger ribonucleic acid and postprandial secretion of glucagon-like peptide- 1 and insulin in rats. Endocrinology 1996;137:3948-56.

47 Tappenden KA, McBurney MI. Systemic short-chain fatty acids rapidly alter gastrointestinal structure, function, and expression of early response genes. Dig Dis Sci 1998;43:

48 Roberge JN, Brubaker PL. Secretion of proglucagonderived peptides in response to intestinal luminal nutrients. Endocrinology 1991;128:3169-74.

49 Thulesen J, Ørskov C, Holst JJ, et al. Short term insulin treatment prevents the diabetogenic action of streptozotocin in rats. Endocrinology 1997;138:62-8.

50 Tanaka R, Matsuyama T, Shima K, et al. Half life of gastrointestinal glucagon-like immunoreactive materials. Endocrinology fapan 1979;26:59-63.

51 Lund PK, Hoyt E, Simmons JG, et al. Regulation of intestinal glucagon gene expression during adaptive growth of small intestine. Digestion 1993;54:371-3.

52 Fischer KD, Dhanvantari S, Drucker DJ, et al. Intestinal growth is associated with elevated levels of glucagon-like peptide 2 in diabetic rats. Am $\mathcal{F}$ Physiol 1997;273: E815-20.

53 Jervis EL, Levin RJ. Anatomic adaptation of the alimentary tract of the rat to the hyperphagia of chronic alloxandabetes. Nature 1966;210:391-3.

54 Hernandez L, Briese E. Analysis of diabetic hyperphagia and polydipsia. Physiol Behav 1972;9:741-6.

55 Mayer J. Genetic, traumatic and environmental factors in the etiology of obesity. Physiol Rev 1953;33:472-508.

56 Schedl HP, Wilson HD. Effects of diabetes on intestinal growth in the rat. F Exp Zool 1971;176:487-96.

57 Clarke RM. Progress in measuring epithelial turnover in the villus of the small intestine. Digestion 1973;8:161-75. 